REVISTA DE ESTUDOS EM ARTES CÊNICAS

E-ISSN 2358.6958

\title{
O que foi que aconteceu? Inventário artístico-pedagógico do ensino do teatro fluminense nos tempos de pandemia
}

Janaína Meira Russeff

\section{Para citar este artigo:}

RUSSEFF, Janaína Meira. O que foi que aconteceu? Inventário artístico-pedagógico do ensino do teatro fluminense nos tempos de pandemia. Urdimento Revista de Estudos em Artes Cênicas, Florianópolis, v. 3, n. 42, dez. 2021.

do) DOI: http:/dx.doi.org/10.5965/1414573103422021e0115

Este artigo passou pelo Plagiarism Detection Software | iThenticate 


\title{
O que foi que aconteceu? ${ }^{1}$ Inventário artístico-pedagógico do ensino do teatro fluminense nos tempos de pandemia
}

Janaína Meira Russeff²

\begin{abstract}
Resumo
Esta pesquisa, de cunho qualitativo, apresentou um inventário artísticopedagógico das práticas e ações de artistas-docentes nos tempos de pandemia. Portanto, refletiu, por meio de um traçado crítico e esperançoso, sobre o que aconteceu no primeiro semestre do ano de $2020 \mathrm{com}$ o ensino do Teatro na Educação Básica fluminense. Sempre atento às vozes de professores e consubstanciado por referências teórico-documentais, este artigo identificou o protagonismo dos professores que assumiram, muitas vezes, sem que se dessem conta, a condição de pesquisadores, autores, produtores de saberes emergenciais e protagonistas desse momento inédito de nossa história.
\end{abstract}

Palavras-chave: Ensino do teatro. Pedagogia do teatro. Ensino remoto.

\section{What happened? An artistic-pedagogical inventory of drama teaching in Rio de Janeiro in times of pandemic}

\begin{abstract}
This qualitative research presents an artistic-pedagogical inventory of the practices and actions of artist-teachers in times of pandemic, in Rio de Janeiro, Brazil. It reflected, through a critical and hopeful outline, on what happened in the first semester of 2020 with the teaching of Drama in Basic Education in the state of Rio de Janeiro. Always attentive to the voices of teachers, and substantiated by theoretical-documentary references, this article identifies the protagonism of teachers who assumed, often without realizing it, the condition of researchers, authors, producers of emergency knowledge and protagonists of this unprecedented moment of our history.
\end{abstract}

Keywords: Drama teaching. Drama pedagogy. Remote teaching.

Este artigo é resultado do Trabalho de Conclusão de Curso (TCC) do curso de especialização Saberes e Práticas na Educação Básica - CESPEB/UFRJ, Ênfase em Ensino Contemporâneo de Arte. Intitulado: O que foi que aconteceu: Registros de saberes e práticas emergentes de artistas-docentes de teatro nos tempos de pandemia e defendido em novembro de 2020.

${ }^{2}$ Mestrado em Ensino das Artes Cênicas pela Universidade Federal do Estado do Rio de Janeiro (UNIRIO). Especialização em Educação pala Universidade Federal do Rio de Janeiro (UFRJ). Licenciada em Teatro pela mesma Universidade. Professora da educação básica na rede pública e privada do Rio de Janeiro. E-mail: janarusseff79@gmail.com

http://lattes.cnpq.br/9454823991136660 


\section{¿Qué fue lo que pasó? Inventario artístico-pedagógico de la docencia en Teatro de Río de Janeiro en tiempos de pandemia}

\section{Resumen}

Esta investigación cualitativa presentó un inventario artístico-pedagógico de las prácticas y acciones de los artistas-maestros en tiempos de pandemia. A través de un esquema crítico y esperanzador, reflexionó sobre lo ocurrido en el primer semestre de 2020 con la docencia del Teatro en Educación Básica en lo estado de Rio de Janeiro, Brasil. Siempre atento a las voces de los docentes y sustentado en referencias teórico-documentales, este artículo identificó el protagonismo asumido por los profesores que asumieron - muchas veces sin darse cuenta - la condición de investigadores, autores, productores de conocimientos de emergencia y protagonistas de este momento inédito en nuestra historia.

Palabras clave: Docencia teatral. Pedagogía teatral. Enseñanza remota. 
Há muito, muito tempo, os seres humanos não podiam olhar para cima, porque o céu era demasiado baixo. Os pássaros não conseguiam voar, as árvores não cresciam direito e os homens tinham que andar curvados para frente enxergando apenas os seus pés. As crianças escapavam da maldição que afligia os adultos, porque elas eram muito pequenas. Mas elas sabiam que um dia também se tornariam adultas e teriam que andar curvadas enxergando apenas seus pés.

Uma noite, todas as crianças se reuniram e decidiram levantar o céu usando varas longas. Quando ficaram sabendo, os adultos começaram a rir. Porém, quando viram as crianças erguendo suas varas para o céu, eles ficaram em dúvida. Mas o céu não se moveu.

No dia seguinte, as crianças foram procurar varas mais longas, muito mais longas, e retomaram o trabalho. Apesar de seus corajosos esforços, o céu não se moveu. No outro dia, as crianças, ainda mais motivadas, trouxeram uma vara tão grande que não se enxergava a sua ponta. As crianças começaram a empurrar, empurrar, empurrar e com um grande estrondo, o céu se ergueu.

Desde daquele dia, o céu está onde o vemos hoje. As árvores puderam crescer, os pássaros ficaram livres para voar e as nuvens passeiam à vontade. E os homens, pela primeira vez, puderam ficar de pé e contemplar o céu. A coisa mais extraordinária que aconteceu, foi que quando os espíritos da noite saíram da planície, o céu, furado pelas varas dos homenzinhos começou a cintilar, em cada furo havia uma estrela.

(História do povo apache) $)^{3}$

\section{Notícias de uma pandemia ${ }^{4}$}

Era uma sexta-feira, treze (!) de março de 2020, quando o governo do Estado do Rio de Janeiro divulgou as medidas temporárias de prevenção ao contágio e de enfrentamento da propagação decorrente do novo coronavírus (Covid-19). Tais medidas, entre outras orientações, suspendiam as atividades coletivas e culturais e as aulas presenciais na educação básica e superior, da rede pública e privada de ensino, por quinze dias.

Puxando os fios da lembrança e rememorando esse momento, recordo-me

${ }^{3}$ História transcrita do curta-metragem Hugh, o índio Apache - A história do grande céu.

${ }^{4}$ Revisão ortográfica e gramatical do artigo realizada por Vanusa Rodrigues da Silva. Mestra em ciências sociais - Cpdoc/FGV - 2019. Graduada em Letras - Português/Literaturas (UFRJ - 2003). 
de que, ao receber tal informação, estava a caminho do ensaio da peça de teatro que estrearia em abril. A notícia chegou com o telefonema do diretor pedagógico da escola particular na qual trabalho. Por telefone, o coordenador comunicou-me a suspensão temporária das aulas presenciais e solicitou que eu organizasse roteiros de estudos a serem enviados aos alunos, na segunda-feira, dia dezesseis de março. Finalizamos a ligação, nos despedimos e marcamos um encontro em quinze dias.

A informação me pegou um tanto desprevenida, pois, embora acompanhasse as notícias dos casos de contaminação e morte vindas dos países europeus e asiáticos, aquela realidade parecia ainda distante para mim. Cheguei ao meu destino e o assunto era o decreto do governador e, consequentemente, a suspensão dos nossos ensaios por quinze dias. Pairava no ar um certo otimismo. Acreditávamos que, em duas semanas, estaríamos de volta. O ensaio acabou, nos despedimos e seguimos com a certeza de que nos encontraríamos em breve.

Reporto-me, aqui, a esses dois eventos, porque são marcos iniciais da minha memória pandêmica. Ambos, coincidentemente, encerraram-se com a certeza de um reencontro breve que não aconteceu. Arrisco-me a dizer que esse foi o momento da queda do meu céu. Queda essa que, embora há muito estivesse anunciada, me deixou desnorteada e sem chão por um longo período.

Os projetos artísticos, acadêmicos e pessoais, traçados e sonhados para aquele 2020 que se iniciava, foram suspensos e minha vida passou a se constituir, em período integral, de atividades como planejar, orientar e produzir infindáveis aulas mediadas pela tecnologia. De um dia para o outro, o escritório da minha casa se transformou em sala de aula, espaço de reunião e estúdio em tempo integral. A separação entre casa e trabalho deixou de existir e os planos para o futuro ficaram incertos e distantes.

Recordo-me desse momento como uma paisagem difusa, com luz escura (embaçada) e tintas carregadas de cinza e azul escuro. Sentia-me apenas uma apertadora de parafusos espanados, uma enxugadora de gelo, uma funâmbula tentando me equilibrar na corda bamba da educação remota. Aquele cenário era desolador. Não havia uma diretriz ou um projeto artístico-pedagógico para nos 
orientar, apenas adaptávamos as aulas presenciais a roteiros de estudos e videoaulas; em geral, carregados de conteúdos teóricos e apartados da prática e da reflexão artística e sensível.

A cada videoaula ou roteiro produzidos, eu tinha certeza de que aquela não era a aula de Teatro em que eu acreditava. Lembro-me de conversar com outros colegas de profissão e o sentimento de todas e todos era de total falta de perspectiva. Como ensinar Teatro de maneira remota? Será que o teatro resistiria a esse golpe? O que estamos trabalhando, teatro ou audiovisual? Qual o lugar da Arte no ensino remoto?

Para mim, o ponto de virada desse momento inicial de incertezas aconteceu quando me deparei com o artigo do pesquisador Wilson Cardoso Júnior (2020), Artes Visuais em tempos de pandemia. No artigo, Cardoso Júnior faz um inventário imagético das produções artísticas da pandemia da Covid-19 e reflete sobre a maneira como as artes visuais registraram as pandemias do passado e projetaram cenários do futuro. A leitura desse trabalho me impactou e me convidou a indagar: Quem fará o registro de nossa época na área da arte-educação? Contaremos a história ou deixaremos que contem por nós? Restará, a nós, professores, tão somente, as lamúrias de sujeitos inertes, meros espectadores desterrados de nossa história?

Inspirada em Ailton Krenak, em Paulo Freire e também em Augusto Boal (2002), procurei responder a tais indagações. Freire (1997) sublinha que há de se ter esperança para vislumbrarmos outros mundos possíveis. Krenak (2019) nos convida a empurrar o céu para respirarmos quando ele estiver nos sufocando. Boal (2002, p. IX), por sua vez, afirma que "todos os seres humanos são atores, porque agem e espectadores, porque observam”, mas que se faz necessário tornar-se "espect-atores", sujeitos atuantes e transformadores de nossas realidades, e não espectadores passivos das verdades apresentadas. Os três autores nos mostram, portanto, que é na praxis que tensionaremos as transformações.

Seguindo essa linha de raciocínio, e na certeza de que pretendia fazer parte dessa história como "espect-ator[a]", comecei a buscar maneiras de investigar, indagar, registrar e inventariar esse momento inédito em que vivíamos. Para pôr 
em prática tal pretensão crítica e transformadora, criei algumas ações, a fim de dialogar com meus pares (artistas, professores e pesquisadores) e tentar caminhar de modo mais propositivo por esse semovente caminho pandêmico.

A primeira iniciativa foi a de reativar um antigo perfil no Instagram, Professores de Artes Cênicas ${ }^{5}$, por intermédio do qual convidei os professores a partilharem suas práticas artístico-pedagógicas e suas inquietações e aflições sobre ser professor de Teatro em tempos de aulas remotas. A segunda, foi a criação do perfil, também no Instagram, Arte em Tempos de Pandemia6; um diário poético virtual cujo objetivo era o de construir um arquivo artístico-poético, sobre o surto da Covid-19, na perspectiva dos artistas-docentes de Arte da Educação Básica. A terceira ação foi realizar entrevistas, que será objeto de análise desta pesquisa, com os professores de Teatro, das redes pública e privada de ensino do Estado do Rio de Janeiro, que estavam atuando nesse período, a fim de acompanhar mais de perto e melhor entender o que estava acontecendo no processo de ensino-aprendizagem em Teatro, praticado em nosso Estado.

Com essas ações, desenvolvi esta pesquisa com o propósito acadêmico - e pessoal - de ser um trabalho voltado para o futuro e não para o passado. Desejando, antes de mais nada, ser plano de investigação e reflexão que espera contribuir com um novo olhar e outras utopias para o ensino do Teatro na educação básica, ora conturbado por uma pandemia, por um ensino remoto e marcado por profundas desigualdades educacionais e sociais.

Tomando a lenda apache, apresentada na epígrafe desse artigo, como costura poética, procurarei traçar, nas linhas que seguem, o cenário pandêmico do primeiro semestre de 2020 e as ações e tensões das professoras e professores de Teatro da educação básica por esse movediço e desolador caminho.

${ }^{5}$ Como resultado, interagiram professores do Rio de Janeiro, de São Paulo, Rio Grande do Norte, Pernambuco, Alagoas, Paraná e Rio Grande do Sul, entre outros. 


\section{A queda do céu}

No dia 20 de março de 2020, o Senado brasileiro aprovava o decreto legislativo reconhecendo o estado de calamidade pública no Brasil em decorrência do novo coronavírus. Iniciava-se aí a longa e turbulenta história brasileira diante do surto da doença que passaria a se denominar Covid-19, que perdura por meses e totaliza milhares de mortos e infectados por todo o País.

Sob a condução de um presidente que insiste em minimizar a gravidade do vírus, chamando-o de "gripezinha" e promovendo tratamentos sem comprovação médica e resultados científicos, desde então, o Brasil passou a viver uma profunda crise social, sanitária, econômica (talvez a maior de nossa história), ambiental, cultural, moral e política. Diante de um desconcerto social sem precedentes, o governo não apresentou um plano de ação sólido - sanitário, educacional e econômico - e seguiu apostando na estratégia de incentivar a população à retomada das atividades produtivas para aquecer a economia. Tomado por teses obscurantistas, reafirma a sua crença na "imunidade de rebanho" e no tratamento precoce; indiferente ao custo de vidas a serem sacrificadas em nome dessa miragem. Enfim, assistimos horrorizados a uma política de governo que prioriza a equação perversa da dívida acima da vida, contrariando as determinações sanitárias e os princípios éticos, ao abandonar o País à própria sorte no epicentro da pandemia.

Como sinaliza a antropóloga Lilia Schwarcz (2020c), a pandemia evidenciou uma guinada autoritária e a ascensão de um discurso negacionista no Brasil e no mundo:

Houve um movimento grande nas redes sociais, que democratizaram, de um lado, a informação e, de outro lado, a falta de informação, porque as pessoas não se preocupam em verificar a fonte. A lógica das redes é a do imediatismo, sem respeito à produção de conhecimento. E pesquisas mostram que em países desiguais, como o nosso, a política de negacionismo tende a ter mais sucesso, porque há uma lacuna de conhecimento. (Schwarcz, 2020).

\footnotetext{
${ }^{7}$ Fala proferida em pronunciamento oficial, do dia 24 de março, em que o presidente Jair Messias Bolsonaro chama o vírus de "gripezinha", ressalta seu histórico de atleta e minimiza a gravidade da situação em um momento em que o vírus se alastrava por todo o território nacional.

Disponível em: https://youtu.be/VWsDcYK4STw. Acesso em: 11 maio 2021.
} 
Como podemos depreender das observações da antropóloga, a tônica negacionista, além de refutar a história, perpetua um discurso capitalista, patriarcal, racista, neocolonialista. Não podemos esquecer as falas do presidente sobre o uso da máscara: "- É coisa de viado"8; sobre a sua convicção de que o vírus não mata quem tem "histórico de atleta"; sobre a sua frieza e suspeitíssimo humor diante dos milhares de vítimas da Covid-19, em sua maioria de classes menos favorecidas: “- Eu sou Messias, mas não faço milagre!”’10.

Para Schwarcz (2020a), ainda, a "pandemia deixou claro como todos nós somos humanos e vulneráveis" e, sobretudo, no caso do Brasil, escancarou as nossas desigualdades, mostrando como as populações de baixa renda sofrem muito mais. Sofrem, porque não têm equipamentos urbanos suficientes, porque não contam com saneamento básico, porque não têm acesso à saúde púbica de qualidade, porque não têm seguridades sociais e trabalhistas. Sofrem, enfim, porque são desassistidas.

Ao fazer essa análise assertiva sobre os tempos pandêmicos, Schwarcz sinaliza que estamos em um momento de ruptura e de transição entre séculos. A propósito, para a autora, a crise causada pela disseminação da Covid-19 marca o fim do século XX, tal como para Hobsbawn, o fim do século XIX não se deu na transição cronológica dos anos 1800 para 1900¹1. Ancorada nesse raciocínio, Schwarcz afirma que o século XXI se iniciará quando a pandemia acabar:

O que a Primeira Guerra mostrou? Que [o mundo] não era tão civilizado quanto se imaginava. Pessoas se guerreavam frente a frente. $E$ isso mostrou, naquele momento, o limite da noção de civilização e de evolução, que era talvez o grande mito do final do século 19 e começo do 20. E nós estamos movendo limites. Investimos tanto na tecnologia, mas

${ }^{8}$ Disponível em https://www.correio24horas.com.br/noticia/nid/mascara-e-coisa-de-viado-dizia-bolsonaroantes-de-pegar-covid-19/ Acesso em : 11maio 2021.

${ }^{9}$ Disponível em https://youtu.be/VWsDcYK4STw Acesso em: 11 maio 2021.

${ }^{10}$ Disponível em https://youtu.be/T kl-EMGkOw . Acesso em: 11 outubro 2021

${ }^{11}$ Eric Hobsbawn disse que o longo século XIX só terminou em 1918, com o fim da primeira guerra mundial. Acreditava-se no progresso e na evolução [...]. No entanto, a primeira guerra mostrou como esses mesmos povos estavam mais próximos da barbárie e da destruição. Por isso, Hobsbawn tem razão: os séculos não terminam com o virar da folhinha do calendário, mas quando grandes crises colocam em questão verdades que já pareciam estabelecidas (Schwarcz, 2020a, p.5). 
não em sistemas de saúde e de prevenção que pudessem conter esse grande inimigo invisível (Schwarcz, 2020b).

A pandemia, portanto, deixa expostas todas as feridas de uma sociedade que se fiou no discurso da tecnologia para construir o imaginário coletivo de um povo civilizado, mas que ainda é excludente e segregador.

Com essa perspectiva crítica que coloca nosso tempo sob suspeita, busco dialogar com o educador António Nóvoa (2020) para refletir sobre as feridas abertas no campo da Educação. Segundo ele, a pandemia denotou o avanço de duas grandes tendências interligadas, que vêm tomando corpo nos últimos vintes anos: a privatização e a inserção do setor privado nas políticas educacionais brasileiras.

A privatização a que Nóvoa se refere não é entendida no sentido clássico do termo, mas como uma redefinição educacional, ou seja, como um bem privado. Entendimento trazido por uma das tendências identificadas pelo pesquisador:

Espécie de um crescente individualismo, de uma crescente concepção da educação como um bem privado. A ideia de que há uma relação de consumo com a educação. Em que os pais escolhem a melhor educação a dar individualmente aos seus filhos e estabelecem, portanto, uma relação que podemos designar de consumista da educação. Como se a educação fosse apenas um serviço que se presta a um conjunto de crianças no plano individual (Nóvoa, 2020).

Para Nóvoa, algumas correntes teóricas e científicas contribuíram, de certa maneira, para reforçar essa visão da educação como serviço: "Os estudos sobre o cérebro e as aprendizagens, extraordinariamente importantes, acabaram por trazer essa dimensão de personalização, de falar cada vez mais de aprendizagem e menos de educação" (Nóvoa, 2020).

Percebemos nas considerações de Nóvoa, que essa compreensão mais centrada no "como ensinar", por vezes, pode desconsiderar a importância do caráter coletivo e socializador no processo de ensino-aprendizagem. Como bem nos lembra Paulo Freire, em sua Pedagogia da Autonomia, "ninguém educa ninguém, como tampouco ninguém se educa a si mesmo: os homens se educam em comunhão, mediatizados pelo mundo" (2011, p.96). Logo, o ensino é construído 
de forma compartilhada, coletiva e atravessado permanentemente pelo contexto histórico, social e cultural em que se encontra.

Refletindo sobre a educação brasileira, podemos identificar essa compreensão estrita de aprendizagem, mais centrada nos processos cognitivos, nos movimentos homeschooling (ou ensino doméstico) e "Escola Sem Partido". Tais movimentos, que vêm ganhando força nos últimos anos, têm como ponto de interseção a reivindicação de uma educação neutra e sem viés ideológico "ideologia de gênero" e "doutrinação marxista”, por exemplo - que esteja de acordo com as convicções, religiosas e morais, de cada família. Uma educação "asséptica" e descolada da realidade social em que está mergulhada, mais preocupada com a aprendizagem pragmática, como sinônimo de qualidade de ensino, que vislumbra um professor gerenciado e cerceado. Mas seria importante considerar que o discurso da neutralidade política traz, inextricavelmente enredado, o contraponto de um outro discurso, também profundamente político e ideológico.

Podemos perceber que os dois movimentos corroboram o pensamento de "privatização", na perspectiva de Nóvoa, mas também observamos uma privatização no sentido clássico, ao se tentar tirar do Estado o dever com a educação, conforme previsto na Constituição Brasileira de 1988:

A educação, direito de todos e dever do Estado e da família, será promovida e incentivada com a colaboração da sociedade, visando ao pleno desenvolvimento da pessoa, seu preparo para o exercício da cidadania e sua qualificação para o trabalho (Brasil, 1988, Art. 205).

Tais movimentos procuram nos convencer de que a família está acima do Estado na definição da educação, o que fere o princípio constitucional da isonomia e da universalidade, reiterados pela Lei de Diretrizes e Bases (LDB/96) e Estatuto da Criança e do Adolescente (ECA).

Esta maneira de compreender a educação vai de encontro à concepção de educação pública e republicana compreendida como direito de todos e dever do Estado. A par disso, desconsidera a complementaridade entre Estado e família no dever de ensinar, e não reconhece a educação básica como obrigatória, laica, 
universal (para todos), única e indispensável ao pleno desenvolvimento humano, como propugnado, em 1932, no Manifesto dos Pioneiros da Educação Nova, e consagrado na Constituição Federal e nas Leis de Diretrizes e Bases que se sucederam.

Ainda na esteira reflexiva sobre privatização, António Nóvoa identifica outra tendência que vem crescendo nas entrelinhas da educação, nos últimos vinte anos, e ora revelada pela pandemia: a inserção do setor privado - empresas digitais como Gafan² e instituições sem fins lucrativos - na gestão das políticas educacionais.

Essas grandes empresas digitais, instituições e fundações foram se constituindo em parte importante da educação, reforçando as concepções empresariais de gerenciamento, pautadas na meritocracia, sob os lemas de "novo", "moderno", "eficiente", "eficaz" e "responsável” em detrimento da experiência e formação dos profissionais das próprias instituições acadêmicas e as de ensino básico. Dessa forma, contribuem sobremaneira para a difusão de ideias que têm promovido e perpetuado processos de privatização e desvalorização da profissão docente durante os últimos vinte anos.

Essa transferência da responsabilidade das políticas educacionais para as instituições privadas, portanto, foi mais uma ferida exposta durante a pandemia que mostrou o despreparo dos poderes públicos para lidar com o caos. A falta de um plano de ação educacional para orientar e balizar a educação remota, no que diz respeito ao ensino e ao acesso, evidenciou o obscuro cenário de omissão e incapacidade administrativa do Estado, em tempos pandêmicos.

O Ministério da Educação (MEC), em um moroso processo de implementação de políticas emergenciais para a educação, adotou como solução o ensino a distância através de meios digitais, ao homologar no dia 1o de junho de 2020 (quase três meses depois da suspensão das aulas) um conjunto de diretrizes aprovadas pelo Conselho Nacional da Educação (CNE), em 28 de abril de 2020 (!), com o objetivo de orientar estados, municípios e escolas sobre as práticas a serem adotadas durante a pandemia.

12 Google, Amazon, Facebook, Apple e Microsoft. 
Porém, tais medidas foram adotadas sem levar em consideração as complexas realidades socioeconômicas ${ }^{13}$ dos estudantes das diferentes regiões do país e as experiências dos professores que, paradoxalmente, foram indispensáveis para que ações educativas, mesmo que deficitárias, acontecessem nesse período. Relegou-se, portanto, milhares de alunos e alunas à condição de excluídos da educação, o que, certamente, poderá contribuir para agravar ainda mais as desigualdades sociais em um futuro próximo.

Com a ausência de uma coordenação nacional para dar uma resposta igualitária às redes de ensino e garantir a isonomia do acesso à educação, revelouse um cenário preocupante em que as desigualdades da educação tornaram-se ainda mais visíveis e dramáticas. Enquanto as escolas particulares saíram na frente, implementando suas plataformas e metodologias, as escolas públicas sequer conseguiram resolver uma questão crucial: a acessibilidade. O resultado foi um verdadeiro "apagão" no ensino que evidenciou e ampliou as desigualdades entre o ensino público e privado em todo o País.

Como refletido e argumentado até aqui, e seguindo a linha de raciocínio de Lilia Schwarcz, a pandemia deixa evidentes as fraturas expostas de uma sociedade que tem à disposição infinitos recursos tecnológicos e científicos, mas se mostra desumana e desigual. Escancara, portanto, um projeto falido de sociedade, em que as coisas valem mais que as pessoas, que se fiou na tecnologia como aparato libertador e emancipador, mas que se mostra incapaz de assegurar os direitos fundamentais dos indivíduos, privando-os do exercício pleno da cidadania conforme previsto em nossa Constituição Federal (1988) e na Declaração de Direitos Humanos.

Mas o que fazer diante dessa cadeia trágica de acontecimentos e fatos? Será possível sair desse estado catatônico? Paulo Freire nos fala da importância imperativa da esperança para a existência individual e social, pois "a desesperança nos imobiliza e nos faz sucumbir ao fatalismo onde não é possível juntar as forças

\footnotetext{
${ }^{13}$ Segundo o TIC Domicílios, estudo que mede os hábitos e comportamento de usuários da internet brasileira, um em cada quatro brasileiros não tem acesso à internet. O levantamento mostra ainda que 58\% dos internautas brasileiros se conectam exclusivamente pelo telefone celular. $85 \%$ dos usuários das classes D e E se conectam exclusivamente pelo aparelho móvel. A taxa de usuários que usam exclusivamente o celular é um indicativo importante, pois nem sempre os aparelhos permitem a realização de atividades mais complexas.
} 
indispensáveis ao embate de recriar o mundo" (Freire, 1997, p.5). Esperança essa ancorada na prática e acompanhada de um olhar crítico e histórico, pois, enquanto necessidade ontológica ela precisa da prática para torna-se concretude histórica. Do contrário, ela, a esperança, vira desesperança, porque "não há esperança na pura espera, nem tampouco se alcança o que se espera na espera pura, que vira assim espera vã” (Freire, 1997, p.6).

Assim, talvez seja importante projetar luz nesse caos, para enxergarmos, nas fissuras causadas pela pandemia, a possibilidade de esperançarmos. Ora, se por um lado a pandemia escancara as feridas abertas, por outro lado, evidencia pontos de cisão, no desenrolar dessa história que, talvez, nos possibilitem lançar um novo olhar sobre nosso tempo. Um olhar contemporâneo, como nos propõe o filósofo Agambem (2009), capaz de estabelecer uma relação singular com seu tempo, aderindo-se a ele e, ao mesmo tempo, tomando distância para, assim, ser capaz de fazer uma leitura crítica da realidade em que está submetido.

Esse é o ponto de inflexão dos atuais tempos pandêmicos: observar no caos que nos tomou de maneira intempestiva fugas e escapes para construirmos o porvir. Conviria, portanto, submeter o nosso tempo à desconfiança crítica do olhar contemporâneo para, como nos convida a refletir Ailton Krenak (2019), repensarmos as premissas da nossa sociedade e, quem sabe, tramarmos histórias e "ideias para adiarmos o fim do mundo".

Lilia Schwarcz (2020ā , p.12), que se diz "pessimista no atacado e otimista no varejo", aposta que, se cada um exercer sua cidadania, sua vigilância cidadã, a gente pode dar sorte no azar e fazer dessa crise uma oportunidade de mudança. Nóvoa, ao afirmar sua convicção de que a educação é a base de uma sociedade democrática, aposta no protagonismo dos professores para traçar os novos rumos da educação pós-pandêmica.

Neste sentindo, esta pesquisadora, que ora se apresenta neste estudo, assim como Schwarcz, também é otimista no varejo; e, como Nóvoa, compreende que o que conta mesmo é a força dos professores e está convencida de que este seja o momento para refletirmos sobre a educação que queremos para o futuro. E isso, porque reconhece a fundamental importância da educação, em todas as suas 
dimensões, para a construção de uma sociedade justa e igualitária. E entende, também, que não há como pensar educação sem trazer para essa reflexão os professores e professoras que atuaram durante este período pandêmico procurando administrar suas inquietações, dúvidas e desânimos, mas também, esperançando e animando-se com suas descobertas e soluções.

Ailton Krenak (2019, p.14) afirmou que "quando você sentir que o céu está ficando muito baixo, é só empurrar e respirar". E, de certa maneira, muitos professores durante esse período assim o fizeram: empurraram o céu! Não se entregaram às soluções digitais pré-preparadas e, tampouco, se renderam à inação. Se num primeiro momento, com a queda do céu, se sentiram imobilizados e incapazes, aos poucos tomaram impulso e deram respostas: empurraram o céu que, de repente, havia caído em suas cabeças. E foi impressionante a maneira como muitos se dispuseram a construir uma rede solidária, composta por professores de diferentes níveis da educação (educação básica, graduação e pósgraduação), interagindo por meio de diversos ambientes virtuais (páginas nas mídias sociais, grupos de WhatsApp, lives, encontros nas plataformas digitais, congressos virtuais etc.) para debater ideias e trocar experiências para lidar com o colapso da educação. Assumiram, muitas vezes, sem que se dessem conta, a condição emergente de pesquisadores, autores, produtores de saberes emergenciais e protagonistas deste momento inédito de nossa história.

Para Maurice Tardif (2012), quando os professores se iniciam em sua profissão, sofrem um "choque de realidade" ao se confrontarem com suas limitações frente à realidade das salas de aula; e "diante desta realidade são impulsionados a encontrar e a desenvolver saberes próprios, alicerçados em suas práticas cotidianas" (Soter da Silveira, 2016, p.71). Saberes esses que Tardif nomeia de "saberes experienciais".

Como pontua Soter da Silveira (2016, p.72), Tardif irá nos dizer que "é a partir dos saberes experienciais que os professores filtram, traduzem e sistematizam os outros saberes, incorporando-os ou abandonando aqueles que julgam desnecessários ou inadequados à realidade do trabalho na escola”. Seguindo essa linha de raciocínio, podemos afirmar que saberes emergenciais produzidos durante a pandemia são os saberes experienciais conceituados por Tardif, pois 
foram produzidos no "choque de realidade" diante do ensino remoto e foram sendo sistematizados através da troca entre os pares.

Em vista desses questionamentos, este é o ponto de interesse desta pesquisa: verificar e identificar quais foram os saberes emergenciais/experienciais desenvolvidos pelos professores de Teatro em tempos de pandemia. E mais especificamente: quais foram os saberes mobilizados e desenvolvidos pelos professores de Teatro da educação básica? Foi possível desenvolver práticas teatrais mediadas pela tecnologia? O ensino parou ou conseguimos desenvolver conhecimento? Enfim, parodiando Drummond, na cota zero da existência em que estamos mergulhados, "a vida parou/ ou foi o automóvel?"

Pesquisar e inventariar esses saberes, pode nos dar pistas e trazer luz para as reflexões sobre o ensino do Teatro na Educação Básica, nos tempos atuais, com vistas a um futuro educacional pós-pandêmico.

\section{Empurrando o céu}

Com o propósito de registrar os fazeres e saberes docentes e investigar de que maneira aconteceu o ensino do Teatro em tempos de pandemia, foram realizadas entrevistas com professores de Teatro que atuam na educação básica fluminense ${ }^{14}$, da rede pública e privada do Estado do Rio de Janeiro. O material levantado será, a seguir, objeto de análise do presente estudo.

Partindo da indagação: Quais foram os saberes construídos pelos professores, diante das demandas da realidade e dos desafios de ministrar Teatro na educação básica, mediados pela tecnologia?; foi elaborado um questionário pautado nos objetivos desta pesquisa e que inclui as seguintes questões: Foi possivel ensinar Teatro de maneira remota?; De que maneira os saberes disciplinares e pedagógicos foram transformados diante da nova realidade?; Qual a participação dos professores na elaboração das estratégias pedagógicas para se ensinar em tempos inéditos? Qual foi a importância da troca entre os pares de

14 O motivo deste recorte deu-se pelo interesse em dar continuidade à pesquisa iniciada no meu mestrado, quando investiguei os processos de formação continuada voltados para os professores de Teatro que atuam na Educação Básica do Estado do Rio de Janeiro. 
profissão nesse momento de crise? De que maneira essa nova experiência impactou a prática docente e o ensino do Teatro?

Para coletar os dados foram realizadas entrevistas semiestruturadas criadas no Google Forms, e enviadas pelas mídias sociais (Facebook, Instagram e WhatsApp); portanto, não foi possível controlar quantas pessoas foram atingidas. Foram recebidas 78 respostas de professores de diferentes partes do País. Após a leitura das devolutivas, foram selecionados 12 professores para participarem dessa análise. A escolha dos professores procurou contemplar professores de diferentes redes de ensino - pública (municipal, estadual e federal) e particular do Estado do Rio de Janeiro e respeitou os seguintes aos critérios:

1. Incluir somente professores que atuam no Estado do Rio de Janeiro;

2. Incluir somente os professores que responderam a todos os itens do questionário;

3. Validar apenas um preenchimento (alguns professores enviaram mais de uma vez o formulário);

4. Incluir professores com Licenciatura Plena em Teatro (foram descartadas formações em Artes Visuais, História da Arte, Bacharelado em Teatro e formação em curso);

5. Incluir professores que trabalham do fundamental 1 ao médio (foram descartados educação infantil, EJA, curso técnico, oficina e graduação);

6. Selecionar as respostas de professores que procuraram a troca (de opiniões, práticas e informações) com seus pares para a elaboração das aulas durante esse período;

7. Incluir apenas professores que responderam ao questionário durante o mês de julho.

Foi utilizada como método de coleta de dados a entrevista on-line assíncrona em que, como pontua Uwe Flick (2009, p. 168), "você envia suas perguntas aos participantes e eles encaminham suas repostas de volta mais tarde: nesse caso vocês não precisam estar conectados ao mesmo tempo". A opção pela entrevista on-line assíncrona deu-se, portanto, por causa do entendimento de que, naquele momento de distanciamento social e de excesso de reuniões e encontros virtuais, abrir um espaço de reflexão escrita, através de uma entrevista assíncrona, seria uma oportunidade para o professor refletir, ao seu tempo e de maneira individual. 
Tendo em vista que para realizar uma pesquisa de pretensões acadêmicas é essencial "promover o confronto entre os dados, as evidências, as informações coletadas sobre determinado assunto e o conhecimento teórico acumulado a respeito dele" (Lüdke e André, 1986, p.1), os procedimentos de análise foram delineados e consolidados à medida em que os dados foram coletados, sistematizados, categorizados e, finalmente, submetidos à análise e interpretação final que constituíram o texto final desta investigação.

Construí, portanto, um texto usando as falas/redações que narram a história não apenas de indivíduos, mas de um grupo de artistas-docentes que lecionaram Teatro na Educação Básica do Estado do Rio de Janeiro em tempos de ensino remoto. A par de todos esses cuidados e precauções, mantive o anonimato dos entrevistados, aqui identificados por letras de A a L (portanto, totalizando 12 professores) + Código da Rede de Ensino em que atuam (1: rede privada, 2: município de Nova Iguaçu, 3: município do Rio de Janeiro, 4: município de Rio das Ostras, 5: Colégio de Aplicação e 6: Rede Estadual). As imagens foram selecionadas, posteriormente, em diálogo com os assuntos analisados nas entrevistas.

\section{O que foi que aconteceu? Registros de saberes e práticas} emergentes de artistas-docentes nos tempos de pandemia

O envio dos questionários, com perguntas abertas, ocorreu na segunda quinzena de julho, período de recesso escolar no Estado do Rio de Janeiro. Esse foi o primeiro momento que, nós professores da Educação Básica, paramos desde que o ensino remoto havia começado. Logo, estamos falando de uma reflexão em retrospectiva, que traz consigo as memórias emotivas da experiência de cada um, mas que convida o entrevistado a perspectivar o futuro.

Ao ler as histórias narradas, deparei-me com trajetórias pandêmicas individuais, de artistas-docentes que atuam em diferentes realidades e redes de ensino, mas que também compartilham reflexões e experiências artísticopedagógicas coletivas afins. Observar as individualidades e as afinidades dos 
sujeitos desta pesquisa pode ser uma boa maneira de iniciar esta análise. Portanto, inicio observando as respostas dadas pelos professores ao serem indagados sobre quais lembranças tinham de quando tudo começou; o começo do começo:

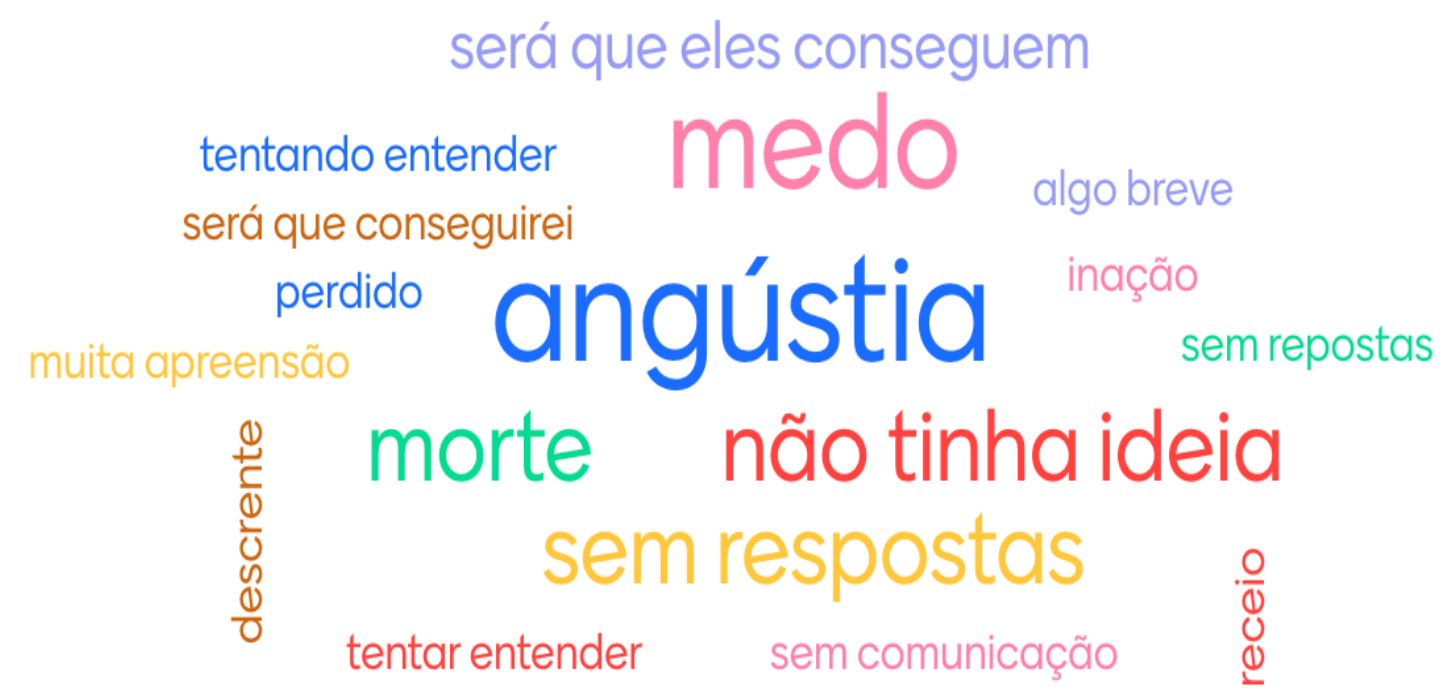

Apresento essa nuvem de palavras, porque é inaugural nesse caminhar, permeado de incertezas, medos e apreensões, mas também marcado por possível força propulsora para que os professores buscassem estratégias e não se rendessem à inação. Esse caminhar será aqui objeto de análise para compreendermos se os professores foram capazes de transformar a inanição em ação, se foram capazes, afinal, de empurrar o céu e respirar, sob uma perspectiva crítica, coletiva e autoral.

Continuo a análise, observando os dados referentes às capacitações ofertadas pelas instituições para que os professores pudessem desenvolver seus trabalhos no formato remoto. Ao analisar os dados sobre a capacitação para a produção das atividades remotas, verificamos o seguinte cenário: quatro professores, A1, C1, E3 e 13, sinalizaram que a instituição "deu pleno suporte: oferecendo cursos de qualidade que auxiliaram no trabalho remoto"; já B1, K3 e F6 sinalizaram que a instituição "deu algum suporte: oferecendo cursos, que, embora insatisfatórios, podem ter ajudado”, enquanto cinco respondentes, J3, D2, H4, G5 e L6, entendem que a instituição "deu pouco suporte: indicando cursos 
gratuitos e sugerindo que o professor buscasse se capacitar por conta própria”.

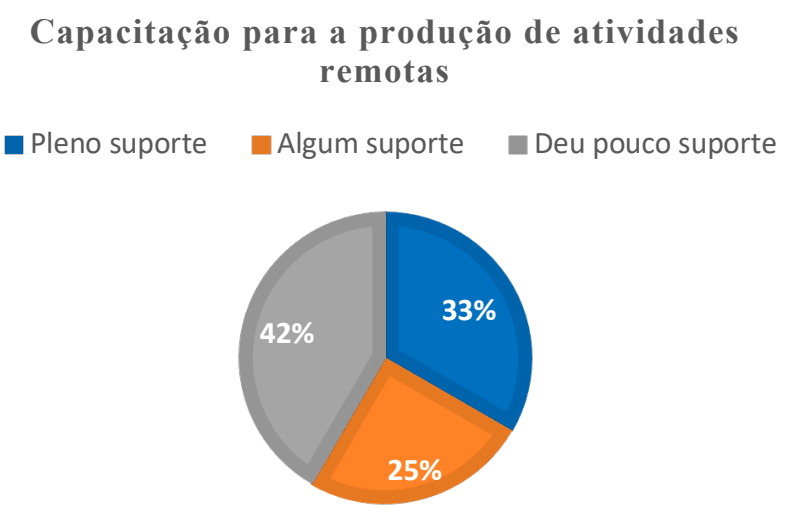

No que diz respeito à capacitação para a veiculação de atividades remotas, seis professores, A1, C1, E3, 13, J3 e F6, consideraram que a instituição "deu pleno suporte: oferecendo plataforma e orientação técnica”, cinco respondentes que , B1, K3, H4, G5 e L6, apontaram que a instituição "deu algum suporte: oferecendo apenas a plataforma”, enquanto D2 sinaliza que "deu pouco suporte: orientando a equipe a utilizar plataformas gratuitas".
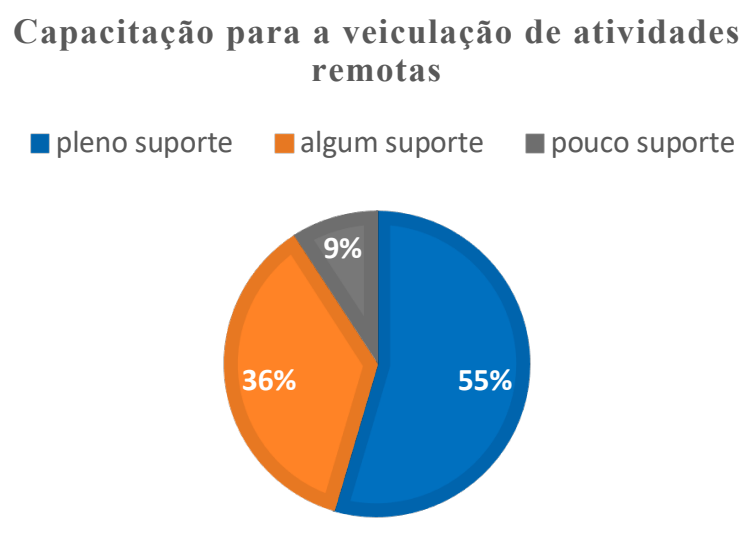

Analisando a imagem acima, pode-se presumir, em uma leitura genérica, que a maioria dos professores teve, mesmo que de maneira insatisfatória, alguma capacitação para a realização, produção e veiculação de suas atividades no 
formato remoto. Observamos no primeiro gráfico que 58\% tiveram alguma capacitação inicial para o uso da tecnologia na produção das aulas e no segundo gráfico que 91\% tiveram orientação para o uso das plataformas. Para compreendermos de que maneira esse apoio inicial efetivou-se verdadeiramente na prática, trago as narrativas dos professores para análise dos dados.

Embora as ferramentas tecnológicas tivessem sido apresentadas, a falta de uma diretriz pedagógica mostrou-se um ponto bastante sensível. Assim, nove dos onze entrevistados ressaltam que as equipes gestoras não apresentaram orientações emergenciais e que, assim como os professores, encontravam-se perdidas para encaminhar as ações pedagógicas. O que causou nesse primeiro momento, principalmente nas escolas públicas, uma morosidade nas ações:

K3: Neste primeiro momento, sem qualquer direcionamento por parte da Secretaria Municipal de Educação e das escolas, compreendi que não seria a hora de propor atividades pedagógicas aos meus alunos. Lembro de me sentir perdido e descrente da comunicação entre escola e famílias.

H4: No primeiro momento, a rede antecipou o recesso de meio de ano e não fez maiores comunicações. Então, minha lembrança foi de ter muitas questões sem resposta, conversando com colegas e tentando projetar possibilidades.

Porém, essa falta de direcionamento pedagógico, de certa forma, oportunizou que os professores participassem ativamente das estratégias; problematizando e apresentando soluções coletivas:

H4: Acho que sim. Havia um desejo da produção audiovisual de material e os professores pediram muito que não [usássemos esse recurso audiovisual] porque haveria muita sobrecarga de trabalho e não teríamos um acesso democrático ao material, já que vários alunos e alunas não possuem equipamentos ou internet.

J3: Acho que não houve uma preocupação em relação às realidades e experiências, mas acredito que há uma tentativa, muitas vezes frustrada, outras vezes acertada. Penso que todos nós, diretores, coordenadores e professores estamos tentando fazer o melhor. No meio disso, é claro, todos muito à flor da pele, sensíveis, gerando ruídos, cegueiras e falta de escuta.

G5: Acho que sim. Porque há uma organização em equipes e departamentos na instituição. Tudo que é aprovado passa por essas instâncias de discussão e deliberação. 
Apenas um professor da Rede Estadual, L6, e um da Rede Privada, A1, sinalizam que não participaram dos planejamentos. O professor A1 ressaltou que a escola já tinha um formato fechado para todas as disciplinas e que não abriu a possiblidade para se pensar as particularidades das aulas de Teatro. "Percebi que isso [a necessidade da disciplina] não está sendo levado em consideração; tem que produzir conteúdo a qualquer custo". Já L6 relatou que a apresentação de um formato fechado, aulas on-line síncronas via Google Classroom, cerceou a autonomia dos professores e impossibilitou a troca entre os pares.

A falta de uma diretriz única instou os professores B1, C1, D2, E3, I3, J3, K3, H4 e G5 a pensarem coletivamente os formatos e as estratégias, junto à sua comunidade escolar e serem autores de suas ações artístico-pedagógicas. Todos os professores relataram ter produzido materiais que consideram inspiradores e importantes para seu desenvolvimento profissional.

Um outro ponto importante a ser observado é sobre qual foi a troca coletiva que passou a acontecer em outros espaços para além das escolas. Todos os professores, até mesmo A1 e L6, apontaram que o fortalecimento do coletivo com a criação de redes solidárias, composta por artistas e profissionais da educação, que emergiram tanto nas unidades escolares quantos nos diversos ambientes virtuais (páginas nas mídias sociais, grupos de WhatsApp, lives, encontros nas plataformas digitais, congressos virtuais etc.), foram fundamentais para que pudessem problematizar a situação da educação e do ofício docente.

D2: Criei um grupo com os professores mais críticos para problematizarmos o que nos ia sendo solicitado.

F6: Se por um lado esse período tem se mostrado caótico pedagogicamente nas escolas da Rede Pública, por outro lado tem aproximado professores que querem construir algo realmente positivo. As infinitas lives e cursos gratuitos virtuais também têm sido super importantes nessa busca.

H4: Percebi que diante das adversidades há mais mobilização da categoria. Mais pessoas se sindicalizaram e estão ativas nas reuniões, propondo ações, agindo de forma mais coletiva. Acho que houve mesmo um "acordar" desses colegas,

E refletir sobre suas ações de maneira a se inspirar e inspirar seus parceiros 
de profissão:

A1: Troco muito com outras professoras no grupo de WhatsApp: música, educação física, biblioteca e computação. Procuro por referências em ambientes virtuais também.

E3: Participei de um fórum da docência UFRJ, que foi bastante produtivo. Colhi ideias bacanas também no perfil de vocês no Instagram.

K3: O tempo todo. Sinto que atualmente minha rede de trocas com educadores amigos e conhecidos precisou se fortalecer. O acesso e a divulgação de algumas de minhas propostas na página do Instagram @professoresdeartescenicas, foi uma fonte de inspirações e contatos potentes.

A par desses relatos, podemos também verificar que, assim como sugere Tardif, foi "através das relações com os pares e, portanto, através do confronto entre os saberes produzidos pela experiência coletiva dos professores, que os saberes experienciais" (Tardif, 2012, p.52) tomaram corpo e adquiriram um certa objetividade. Essa afirmação fica evidente quando os professores percebem que foi na adversidade, no "choque de realidade" e na troca entre os pares que puderam construir saberes e buscar respostas aos problemas coletivos.

Porém, ao serem indagados sobre quais os saberes adquiridos/desenvolvidos durante esse momento que consideram importante e que irão impactar a prática artístico-pedagógica no futuro, apenas cinco, dos onze professores, conseguiram identificar de maneira objetiva os saberes adquiridos:

A1: Edições de vídeos.

B1: Talvez, sim utilizar alguns links de estudos e filmes nas aulas

C1: O contato maior com as tecnologias.

F6: Elaboração de um bom material teórico, literário etc. com o formato virtual.

K3: Sem dúvida, aprender a editar vídeos; dialogar com mais frequência [com] os meios de comunicação e com as referências que os meus estudantes acessam.

Observamos nas respostas dadas que a tecnologia é identificada como um saber adquirido; porém, quando levamos em consideração as experiências 
relatadas pelos professores, é possível observar que os saberes adquiridos vão muito além do domínio da tecnologia:

G5: Através da plataforma da escola, proponho semanalmente jogos, experiências, criações. Deixo sempre um canal para que eles possam se comunicar comigo [...]. São propostas lúdicas semanais, sem obrigatoriedade para os estudantes. Formulo a proposta, gravo um vídeo explicando e posto o vídeo + texto com o mesmo conteúdo.

K3: Elaborei um projeto de Diário Artístico de Quarentena, que pudesse ser abrangente a todas as faixas etárias que acompanho na escola. São vídeos semanais, produzidos e editados por mim, que sugerem aos/as estudantes atividades de caráter artístico/criativo que possam ser experimentados no espaço da casa. Cada atividade explora um aspecto ou tema artístico diferente.

D2: Não está sendo puramente teatro. Ficou muito híbrido agora. O foco é ajudar os alunos com as emoções e compreensão da realidade atual. Então, faço questões, passo vídeos, solicito pesquisas etc.

Podemos observar que esse "choque de realidade" os convidou a repensar os conteúdos, a metodologia e, muitas vezes, o próprio currículo. Ainda que o formato teórico (história do teatro) tenha sido a opção de B1, F6, H4 e L6, os demais professores aproveitaram esse momento para pensar em uma abordagem prática em diálogo com outras linguagens artísticas. Identificamos, portanto, um importante movimento autoral dos docentes, repensando e adaptando, descobrindo e investigando novas possibilidades de criação e relação no formato remoto:

F6: O teatro sendo a arte do presente, me ajuda a trabalhar com o que é possível agora, neste momento. E desse possível, com uma escuta ativa e olhar atento, improvisamos, experimentamos infinitas possibilidades... Muita coisa positiva tem surgido, por incrível que pareça.

K3: O que estamos vivendo, apesar de todo o caráter trágico, é um momento de revisão e de possibilidade de transformação da forma como lemos, atuamos e nos entendemos no mundo, em sociedade. É algo que atravessa a própria ideia de Teatro. Existe um impacto grande na impossibilidade do contato físico, do toque. Mas isso também nos serve como via de jogo (algo que é base na prática teatral, em especial na escola). Penso que é um desafio e uma oportunidade interessante, mas que demanda da gente um certo grau de desapego das formas conhecidas. Eu acredito que o impacto dessas novas formas de interagir no presente com o outro, podem fazer surgir possibilidades de produção artística, de conhecimento, que a gente não percebia na "normalidade". 
Todavia, atentemos também para a falta de unidade pedagógica nas ações, o que acaba transferindo responsabilidades ao professor, além de contribuir para a sobrecarga do trabalho docente. Nove professores, A1, B1, C1, J3, K3, D2, G5, F6 e L6, sinalizam que se sentiram sobrecarregados com o ensino remoto, incluindose os que indicaram ter recebido pleno ou algum suporte (A1, B1, C1, F6 e K3) na capacitação para o uso das tecnologias:

F6: Atividades remotas + infinitas reuniões + preparação de aulas e correção + trabalhos domésticos e crianças pequenas com aulas remotas somados à instabilidade da internet e materiais tecnológicos insuficientes para a família toda.

J3: A sobrecarga vem da situação pandêmica e dessa nova relação entre professor e aluno nesse mundo virtual que é muito um mistério ainda, com recursos que não usava frequentemente, muitos que nunca usei, mas consegui aprender, e outros que ainda não sei utilizar. Na escola pública a situação ainda é pior porque não vejo um retorno concreto dos alunos, ficando, às vezes, a critério alheio o que funciona ou o que não funciona.

K3: A necessidade de ocupar diversas funções para além do planejamento e execução das propostas de aula (como atendimento familiar, edição de vídeo, mobilização do espaço da casa para produzir material de aula, postagem de conteúdo, verificação dos diferentes meios de comunicação diariamente). Somado a tais condições de trabalho, criar uma dinâmica de horários de trabalho no espaço da casa se mostrou, inicialmente, algo complexo.

G5: Pelas condições impostas pela pandemia: serviços domésticos, cuidados com filho, questões psicológicas, tudo isso somado ao trabalho remoto (reuniões, produção de contato com os alunos).

Como podemos depreender das falas acima, a sobrecarga se torna ainda mais complexa quando somada à não problematização do home office e seu impacto na profissão docente. Quando falamos na sobrecarga do trabalho docente, essa é questão comum a todos os professores, tanto da Rede Pública quanto da Privada. Os professores da Rede Privada (A1, B1 e C1) relataram que o excesso de conteúdos a serem trabalhados e a exigência de se produzir material audiovisual, sem uma capacitação que atenda às especificidades da disciplina Arte/Teatro, trouxeram uma sobrecarga imensa para sua rotina profissional, visto que foi necessário aprender a lidar com as tecnologias, produzir material, filmar, editar, além de atender os alunos nas diferentes plataformas. Os professores da 
rede municipal, D2, E3, 13, J3, K3, H4, apontam que a morosidade da Secretaria Municipal de Educação (Rio de Janeiro, Rio das Ostras e Nova Iguaçu) causou uma sobrecarga no trabalho que permeia produção, falta de orientação e a tentativa de manter os vínculos pedagógicos e afetivos com os alunos.

A falta de uma diretriz e de um plano estratégico nacional para lidar com os desafios do ensino remoto, além de contribuírem para a precarização do trabalho docente, evidenciaram as desigualdades da educação. Observamos que, enquanto as escolas particulares saíram na frente, implementando suas plataformas e metodologias, as escolas públicas sequer conseguiram resolver uma questão crucial: a acessibilidade. Todos os professores das escolas públicas (Municipal, Colégio de Aplicação e Estadual) relatam o baixo engajamento e retorno dos alunos:

D2: Estamos alcançando apenas uns 30\% dos alunos e, mesmo assim, nem todos alcançados nos dão retorno.

H4: Nenhuma. Apenas envio materiais sem saber como eles estão, o que causa bastante angústia.

J3: Não tenho contato direto com eles, os vejo raramente pelo grupo do face da escola quando respondem as atividades propostas.

13: Não temos o contato.

K3: Na escola eu acompanho um número grande de estudantes semanalmente, do 10 aos 60 anos do ensino fundamental. São quase 1000 alunos. Mas nesse período, tem sido bem variada a frequência e o contato com ele. A grande maioria está desvinculada da escola.

L6: Incipientes. Pouquíssimos alunos participam e interagem. O reflexo disso é um desânimo geral dos professores que estão sendo obrigados a se desdobrar em novos formatos e terem que dar aula para 1, 2 ou 3 alunos, de turmas com mais de 30.

A imposição de plataformas digitais (Gafan), que dominaram o cenário da educação remota, com soluções prontas e pouco dialógicas com as necessidades pedagógicas, somada à realidade socioeconômica dos estudantes são também fatores que merecem ser problematizados. Embora as escolas particulares, aqui representadas, tenham mantido suas atividades remotas, a falta de um olhar sensível para as necessidades da disciplina Teatro não propiciou um processo de ensino e aprendizagem que contemplasse a linguagem artística, como se 
depreende, por exemplo, das observações de A1 e B1:

A1: Não tenho interação on-line com eles. Tento passar todo meu carinho quando gravo as aulas e quando dou feedback por escrito. Mas sinto que ambos sentimos falta de estarmos juntos ao vivo.

B1: Muito fria ainda hoje, pouco retorno.

As ações da Rede Estadual com a instituição da plataforma Google Classroom são bastante criticadas por L6:

L6: A opção do uso da plataforma do Google Classroom veio de cima para baixo. Inicialmente estávamos usando e-mails com atividades por turma. O uso da plataforma não foi feito de forma a considerar a opinião dos professores. Pouquíssimos alunos participam e interagem. O reflexo disso é um desânimo geral dos professores que estão sendo obrigados a se desdobrar em novos formatos e terem que dar aula para 1, 2 ou 3 alunos, de turmas com mais de 30 .

Nas escolas da rede municipal (Rio de Janeiro, Rio das Ostras e Maricá), aqui analisadas, os professores recorreram a diferentes plataformas digitais, dentre elas as mídias sociais (YouTube, WhatsApp, Facebook e Instagram), visto que as plataformas escolhidas pelas respectivas Secretarias de Educação não eram acessadas pelos estudantes:

K3: A princípio interagi com pouquíssimos pela plataforma Teams, disponibilizada pela prefeitura a partir do mês de maio. Mas percebemos que havia mais facilidade de troca e conversa pelo WhatsApp. Algumas famílias também costumam dialogar e postar devolutivas pela página do Facebook da escola, que está mais movimentada nesse momento. Mesmo assim são poucos os retornos das famílias por ali.

A falta de acessibilidade e a imposição de plataformas digitais que não atendem às especificidades e necessidades do ensino do Teatro, além de relegarem os alunos da Rede pública à condição de excluídos da educação, também impossibilitaram que os professores pudessem refletir sobre a maneira como seus planos e estratégias foram, ou não, bem-sucedidos. Na análise dos dados, foi possível verificar que além dos medos e incertezas com a pandemia, no âmbito pessoal, houve também muitas dúvidas sobre a efetividade do ensino do Teatro mediado pela tecnologia, tanto na rede pública quanto na privada. Quando 
indagados de que maneira este novo formato impactou o fazer e o ensino do Teatro, 50 \%, A1, B1, D2, H4, I3, J3 e L6 afirmaram:

A1: Impossível fazer teatro sozinho.

B1: Virou de ponta cabeça, pois esses conceitos são justamente [os que] não temos agora, pode até ser aula de algum tipo de Arte mas não é Teatro.

D: Totalmente. Posso dizer que o teatro em sua essência foi abstraído.

H4: Nem sei descrever... Os alunos leem apenas, se fazem algo prático o fazem sozinhos, seguindo as minhas instruções como estivessem entendendo; então, de verdade, não são aulas de teatro ou mesmo de arte. É outra coisa.

13: Não temos o contato físico e a escuta não é imediata

J3: Na escola pública impactou totalmente, me sinto triste e de luto.

L6: Totalmente impactado de forma negativa. O não poder olhar nos olhos, anula tudo o que acreditamos que seja teatro feito de verdade. O olho no olho que comunica tudo o que precisamos é inexistente aqui. Os alunos que entram nas aulas desligam suas câmeras, estão em um ambiente com muitas outras interferências externas, não se conectam. O trabalho simplesmente não flui.

Isto posto, talvez seja ainda cedo para mensurar o que fizemos na área da Pedagogia do Teatro, visto que a troca entre professor e aluno, base do processo de ensino e aprendizagem, pouco aconteceu, tanto na rede pública, quanto na rede privada. Diante do abandono do MEC e da inabilidade das Secretarias de Educação para resolver os problemas do ensino remoto, o que se observa é que cada professor, à sua maneira, tentou manter as atividades como podia, administrando suas inquietações, dúvidas e desânimos e procurando se motivar com suas descobertas e soluções.

Embora, seja ainda difícil para todos lançar um olhar contemporâneo sobre o presente, como nos propõe Agambem, ao serem indagados sobre quais os frutos (positivos e negativos) que poderiam ser colhidos em um futuro educacional pós-pandêmico, todos refletiram com sensibilidade, criticidade e esperança sobre o presente e o futuro educacionais: 
A1: Positivo: desenvolvimento de outras estratégias de ensino.

B1: A certeza que o ensino virtual traz algumas ferramentas para ajudar mas não substitui o presencial.

C1: O acesso à tecnologia é positivo. Negativo são os impactos emocionais nos alunos.

D2: Desestabilização é o fruto. Compreender que tudo é impermanente [sic] e saber lidar com isso. Saber viver o presente e pensar soluções para ele.

E3: Depressão ansiedade compulsão alimentar. Espiritualidade consciência respiratória. Poder pessoal. Eu sou. Eu posso.

F6: Positivos: a internet pode aproximar os distantes, pode fornecer conhecimentos valiosos, pode expandir as nossas articulações e compartilhar os nossos conhecimentos etc. Negativo: Educação a distância substituindo a presencial.

G5: A maior valorização da escola presencial. O seu valor está nítido neste momento em que não é possível tê-la.

H4: A pandemia deflagrou todos os absurdos que havíamos naturalizado como falta de água na escola, superlotação de salas, desigualdade de acesso a livros e materiais de estudo. Enfim, tudo! Acho que a categoria está ganhando um pouco mais de consciência não dos problemas, esses todos conheciam, mas do quão absurdos são!

\section{3: Valorizar o momento presente.}

J3: Acho que toda dificuldade costuma gerar um aprendizado, como bem disse Rubem Alves, "ostra feliz não gera pérolas!" Então, acho que logo teremos algumas pérolas por aí...

K3: No campo do ensino das Artes, penso que talvez seja um problema a intensificação de uma crença dessas linguagens como espaço de pura produção, desvinculado da experiência crítica, coletiva e sensível. Se de alguma maneira a escola, como conhecíamos, tende a preterir no currículo as Artes, o momento atual faz ver a necessidade de ampliar sua presença no contexto educativo.

L6: Acredito que todo esse contexto pandêmico veio revelar muitas questões sociais que tentamos disfarçar a maior parte do tempo. $O$ aluno tem um celular, mas não tem acesso à internet. Tem internet mas o seu celular tem uma tela totalmente rachada, não dá pra ler um texto. Alunos não têm comida em casa. Como podemos dar aos alunos condições de aprendizagem quando ele não tem apoio dentro de casa?

Esse olhar sensível-crítico-reflexivo dos professores nos aponta as dimensões dos saberes, constituídos por um conjunto de competências, técnicas 
e experiências, que emergiram e foram constituídos diante do choque da realidade do ensino remoto. Podemos arriscar a compreensão de que, na área da pedagogia teatral, esse choque foi ainda maior, visto que teatro é a arte do efêmero, da presença e do coletivo. Porém, a despeito de tantas dificuldades e precariedades, isto não impossibilitou que buscassem estratégias e soluções para tentar manter o contato afetivo e pedagógico com seus alunos e alunas. Embora, em muitos casos, não seja possível avaliar se suas ações foram assertivas, é possível perceber a emergência de ações e produções autorais desses professores, que diante desse novo formato se viram obrigados a pensar os seus próprios caminhos didáticos e até mesmo metodológicos.

Outro importante ponto que merece a nossa atenção é o senso de coletivo e a consciência profissional desses professores de que são parte da escola, parte desse coletivo de educadores, que constitui a instituição escolar. E que, portanto, são "espect-atores", sujeito atuantes e transformadores de nossas realidades, e não espectadores passivos das verdades apresentadas.

\section{Mirando as estrelas}

Em vista do que foi exposto, conviria reiterar o intricado e delicado cenário enfrentado por todos os professores e professoras durante esse período de pandemia. Um período marcado por uma profunda crise institucional em nosso País, que evidenciou as agudas diferenças sociais, sanitárias, econômicas e educacionais em que vivemos.

Por esse viés compreensivo, procurou-se problematizar, através de um traçado historiográfico e da escuta de professores, a maneira como o ensino do Teatro aconteceu nesse momento de ensino remoto. Constatou-se que o Ministério da Educação não apresentou qualquer tipo de plano emergencial para lidar com a crise e, assim, assegurar a continuidade das aulas de maneira democrática e igualitária no formato remoto. O resultado dessa omissão é um quase apagão da educação brasileira, que só não entrou em um colapso ainda maior devido ao empenho e ao engajamento de muitos professores, a despeito de tantas dificuldades e limitações; esses profissionais foram capazes de interagir em 
uma grande rede solidária e não se deixar imobilizar diante do "choque de realidade" do ensino remoto.

Quando verificamos o que aconteceu com o ensino do Teatro fluminense, mediado pela tecnologia, podemos arriscar o entendimento de que esse choque de realidade foi ainda maior, visto que teatro é a arte do efêmero, da presença e do coletivo. O teatro, enfim, não é arte de solitude; antes, convida à comunhão. Entretanto, nestes tempos sombrios, tal senso coletivo que o fortalece, contraditoriamente o golpeia mortalmente, como ficou evidente nas narrativas da maior parte dos professores entrevistados, descrentes de que tenham feito teatro nesse momento.

Há de se fazer, aqui, uma importante ressalva: embora desacreditem que tenham trabalhado com a linguagem teatral, ao voltarmos a atenção para suas ações e estratégias emergenciais, observamos que tiveram um movimento autoral bastante significativo, repensando e adaptando, descobrindo e investigando novas possibilidades de criação e relação no formato remoto. Ou seja, o teatro sobreviveu em meio ao que estava sendo, muito justificadamente, evitado e temido: a aglomeração de pessoas. O fazer teatral emergiu em diálogo com as diferentes linguagens artísticas e fez parte das proposições artístico-pedagógicas apresentadas pelos artistas-docentes aos estudantes, mesmo de maneira remota.

Assim, em meio a tantas notícias ruins, não podemos negar o valor e a relevância de duas atitudes comuns a todos os professores participantes deste trabalho, provavelmente a espelhar o conjunto desses profissionais: o seu protagonismo, ao darem repostas e criar soluções diante do caos abrupto e inesperado em que se viram mergulhados e o importantíssimo movimento coletivo dos professores que emergiu nos diferentes ambientes digitais e oportunizou que esses profissionais pudessem debater ideias, se inspirar, se fortalecer e continuar existindo e resistindo em tempos, como diria Bertolt Brecht, em que ainda temos que defender o óbvio.

Um movimento coletivo que, assim como as crianças apaches da história que abre este trabalho, buscou infinitas e diferentes estratégias para, com suas varas, empurrarem o céu que havia caído abruptamente em suas cabeças. Infelizmente, 
muitas dessas ações sequer podem ser avaliadas, visto que um dos problemas centrais da nossa educação ainda não foi resolvido: a falta de acessibilidade à internet e aos recursos tecnológicos da grande maioria dos estudantes brasileiros. Porém, sem dúvida, no apagar das luzes provocado pela crise que estamos vivendo, tais ações constituem-se nos pontos luminosos deste momento da nossa história, que cintilarão no céu de um futuro construído por sujeitos que cismam em acreditar que outros mundos são possíveis de serem construídos e imaginados.

\section{Referências}

ANDRE, Marli. O que é um estudo de caso qualitativo em educação? In: Revista da FAEEBA - Educação e Contemporaneidade, Salvador, v. 22, n. 40, p. 95-103, jul./dez. 2013.

AGAMBEN, Giorgio. "O que é o Contemporâneo?" In: O que é o Contemporâneo? e outros ensaios. Chapecó, SC: Argos, 2009.

BOAL, Augusto. Jogos para Atores e Não-atores. Rio de Janeiro: Civilização Brasileira, 2002.

BRASIL. Constituição da República Federativa do Brasil, de 1988. Disponível em: http://www.planalto.gov.br/ccivil 03/constituicao/constituicao.htm. Acesso em: 22/07/2020.

BRASIL. Decreto legislativo que reconhece o estado de calamidade pública. Diário Oficial da União, Brasília, 20 de março de 2020, Seção: 1 - Extra, p. 1. Disponível em: http://www.in.gov.br/en/web/dou/-/decreto-legislativo-249090982

BRASIL. Reorganização do Calendário Escolar e da possibilidade de cômputo de atividades não presenciais para fins de cumprimento da carga horária mínima anual, em razão da Pandemia da COVID 19. CNE/CP no 9/2020, de 28/4/2020 Disponivel em: http://portal.mec.gov.br/index.php?option=com docman\&view=download\&alias=1 45011-pcp005-20\&category slug=marco-2020-pdf\&ltemid=30192

BRASIL. Diretrizes, aprovado pelo Conselho Nacional da Educação (CNE) homologação. Diário Oficial da União, Brasília, 1 de junho de 2020, Edição 103, Seção: 1, p. 32. Disponível em:

https://www.in.gov.br/en/web/dou/-/despacho-de-29-de-maio-de-2020-

$\underline{259412931}$ 
CARDOSO Jr, Wilson. Artes Visuais em tempos de pandemia. Faculdade de Educação - Universidade Federal do Rio de Janeiro, 2020. Disponível em http://www.educacao.ufrj.br/wp-content/uploads/2019/12/NVersao-Arte-em-

Tempos-de-Pandemia.pdf?fbclid=IWAR3prno-1fsaY-

Tx3YOvsYP5uGYUrFS5VhSNnnnhjfCTxZGAf9NZ7ylG7Gw

FLICK, Uwe. Pesquisa Qualitativa online: a utilização da internet. In: Métodos de Pesquisa: Introdução à Pesquisa Qualitativa. Rio de Janeiro: Artmed-Bookman, 2009.

FREIRE, Paulo. Pedagogia da autonomia: saberes necessários à prática educativa. 15. ed. São Paulo: Paz e Terra,1996.

FREIRE, Paulo. Pedagogia da Esperança: reencontro com a Pedagogia do Oprimido. Rio de Janeiro: Paz e Terra, 1997.

KRENAK, Ailton. Ideias para adiar o fim do mundo. São Paulo: Editora Companhia das Letras, 2019.

LUDKE, Menga e ANDRÉ, Marli E. D. A. Pesquisa em educação: abordagens qualitativas. São Paulo: EPU, 1986.

MOREIRA, H e CALEFFE, L. G. Metodologia da pesquisa para o professor pesquisador. 2a. ed. Rio de Janeiro: Lamparina, 2008.

NAVARRO, Mathieu, NOUVEAU, Sylvain, POMMIEZ, François e TURBÉ, Aurore. Hugh o indio Apache - A história do grande céu. In: Site Correio Brasiliense, 2020c. Disponível em: https://www.youtube.com/watch?v=4wt-M46PFq8

NÓVOA, António. Formação de professores para um mundo plural. In: Educar e transformar em tempos de pandemia. Palestra apresentada no Festival do Conhecimento. Rio de Janeiro/UFRJ, 2020. In: Plataforma Youtube

$\mathrm{PL}$ Projeto de Lei 2401/2019. Dispõe sobre o exercício do direito à educação domiciliar, altera a Lei no 8.069, de 13 de julho de 1990 - Estatuto da Criança e do Adolescente, e a Lei no 9.394, de 20 de dezembro de 1996, que estabelece as diretrizes e bases da educação nacional.

https://www.camara.leg.br/proposicoesWeb/prop mostrarintegra;jsessionid=8639 6F8E16039E7E55083D6BCBAB8B71.proposicoesWebExterno2?codteor=1734553\&fil ename $=P L+2401 / 2019$

SCHWARCZ, Lilia. Quando acaba o século XX. 2020a, Breve Companhia.

SCHWARCZ, Lilia. 100 dias que mudaram o mundo. in Site UOL, 2020b. Disponível em: $\quad$ https://www.uol.com.br/universa/reportagens-especiais/coronavirus-100dias-que-mudaram-o-mundo/\#page4

SCHWARCZ, Lilia. Crença em uma cura mágica é comum em pandemias. In: Site Correio Brasiliense, 2020c. Disponível em: 
https://www.correiobraziliense.com.br/app/noticia/politica/2020/07/27/interna p olitica,875636/crenca-em-uma-cura-magica-e-comum-em-pandemias-diz-liliaschwarcz.shtml

SOTER DA SILVEIRA, Silvia Camara. Saberes docentes para o ensino de dança: Relação entre saberes e formação inicial de licenciados em Dança e em Educação Física que atuam em escolas da rede pública de ensino do Rio de Janeiro e da região metropolitana. 2016. Tese (Doutorado em Educação) - Universidade Federal do Rio de Janeiro, Rio de Janeiro, 2016.

TARDIF, Maurice. Saberes docentes e formação profissional. Petrópolis, Editora Vozes, 2012.

TIC Domicilios 2019. Principais Resultados, 2019. Disponível em: https://www.cetic.br/media/analises/tic domicilios 2019 coletiva imprensa.pdf

Recebido em: 13/06/2021

Aprovado em: 26/09/2021 